\title{
Peripheral Cemento-Ossifying Fibroma in Child. A Follow-Up of 4 Years. Report of a Case
}

\author{
Alberto Carlos Botazzo Delbem ${ }^{a}$ \\ Robson Frederico Cunha \\ Janaína Zavitoski Silva ${ }^{b}$ \\ Ana Maria Pires Soubhiac
}

\begin{abstract}
Peripheral cement-ossifying fibroma is a relatively common gingival growth of a reactive rather than neoplastic nature, whose pathogenesis is uncertain. It predominantly affects adolescents and young adults, with peak prevalence between 10 and 19 years. We report here the clinical case of a 5 -year-old girl with disease duration of 3 years, who was followed up for 4 years, showing a gingival health and normal radiopacity of bone. (Eur J Dent 2008;2:134-137)
\end{abstract}

Key words: Peripheral cemento-ossifying fibroma; Pyogenic granuloma; Oral tumors.

\section{INTRODUCTION}

Peripheral cemento-ossifying fibroma (PCOF) accounts for $3.1 \%$ of all oral tumors ${ }^{1}$ and for $9.6 \%$ of gingival lesions. ${ }^{2}$ The pathogenesis of this tumor is uncertain. Due to their clinical and histopathological similarities, some PCOFs are believed to develop initially as a pyogenic

\footnotetext{
1. a Professor, Department of Pediatric Dentistry, São Paulo State University (UNESP) School of Dentistry, Araçatuba, Brazil.

b Postgraduate student, Department of Pediatric Dentistry, São Paulo State University (UNESP) School of Dentistry, Araçatuba, Brazil. c Professor, Department of Pathology and Clinical Propaedeutic, São Paulo State University (UNESP) School of Dentistry, Araçatuba, Brazil.

- Corresponding author: Janaína Zavitoski Silva Department of Pediatric Dentistry, São Paulo State University (UNESP)

School of Dentistry, Araçatuba, Brazil. E-mail: zavitoski_foaldyahoo.com.br
}

granuloma that undergoes fibrous maturation and subsequent calcification. PCOF is frequently associated with irritant agents such as calculus, bacterial plaque, orthodontic appliances, illadapted crowns, and irregular restorations. The mineralized product probably originates from periosteal cells or from the periodontal ligament. $^{3}$

PCOF affects both genders but a higher predilection for females has been reported in the literature. ${ }^{1}$ With respect to race, there is a predominance in whites $(71 \%)$ compared to blacks $(36 \%) .{ }^{4}$ It may occur at any age range, but exhibits a peak incidence between the second ${ }^{5}$ and third decade. ${ }^{6}$ However Neville et al ${ }^{7}$ say that it predominantly affects adolescents and young adults, with a peak prevalence between 10 and 19 years.

Clinically, PCOF manifests as a pediculate or 
sessile nodular mass, which usually originates in the interdental papilla. Its color is similar to that of the mucosa unless the lesion is ulcerated. In this case, the color is bright red and the lesion is frequently confused with pyogenic granuloma. ${ }^{7}$

Most tumors measure less than $2 \mathrm{~cm}$ in diameter, although lesions larger than $10 \mathrm{~cm}$ are occasionally observed. About $60 \%$ of the tumors occur in the maxilla and more than $50 \%$ of all cases affect the region of the incisors and canines. A potential of tooth migration due to the presence of PCOF has been reported. ${ }^{3}$ The treatment of choice is surgical excision, with the specimen being sent for histopathological examination.

\section{CASE REPORT}

Patient A.C.B.S, a 5-year-old black girl, was seen at the Clinic of Pediatric Dentistry, Dental School- São Paulo State University complaining of the presence of a "lump" in the right upper alveolar margin between teeth 52 and 53 . The stepfather reported that the lesion was present for 3 years and had been increasing in volume over time.

No alteration was observed upon extraoral clinicalexamination. Intraoralclinicalexamination revealed a painless, fibrous nodular mass with a sessile base in the right upper alveolar margin extending from the buccal to the palatine side, measuring approximately $1,5 \mathrm{~cm}$ in diameter and showing a rough surface and color similar to that of the adjacent mucosa (Figure 1).

Radiographically, a radiolucent area of undefined limits and discrete bone erosion under the crown of tooth 12 were observed (Figure 2). The differential diagnosis was peripheral giant cell tumor.

Anamnesis showed that the patient had no systemic problem, and surgery was planned on the basis of the clinical and radiographic exams. After extra- and intraoral antisepsis, infiltrative local analgesia was performed. The first incision was made in the buccal side, proximal surfaces and palatine region, including the periosteum. The flap was displaced, the lesion removed and curettage of the area and vigorous scaling of the adjacent teeth were performed (Figure 3). The surgical wound was then irrigated and sutured. The surgical specimen was immersed in $10 \%$ formalin and sent for histopathological examination. Histopathological analysis showed a keratinized stratified pavement epithelium, cellularized connective tissue with areas of a chronicinflammatoryinfiltrate, and mineralization focus resembling cementum (Figures 4 and 5).

Fouryears after surgery, submucosal inclusion of tooth 12 was noted in the oral cavity based on the transparency and normal color of the adjacent mucosa (Figure 6). Periapical radiography showed radiopacity of the bone tissue and apical dilaceration of tooth 12 (Figure 7). Thus, ulotomy was performed in order to release the crown of tooth 12 for eruption.

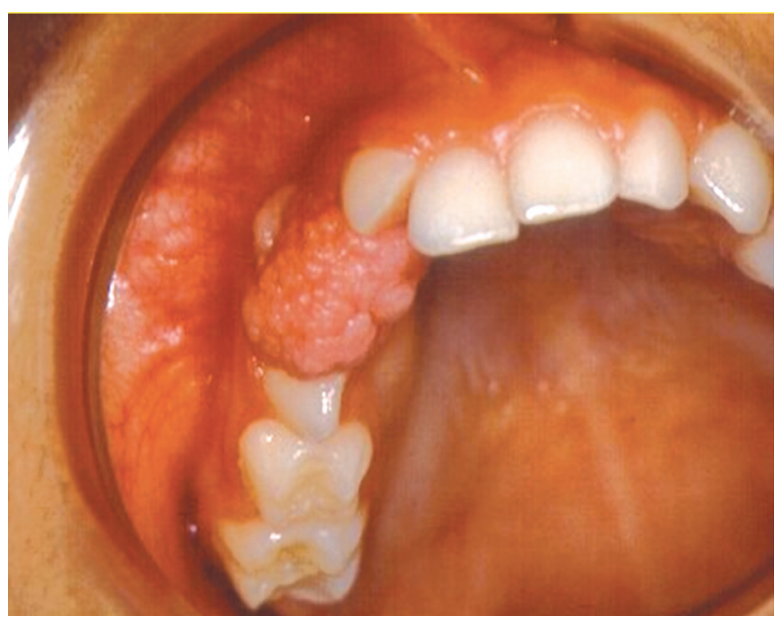

Figure 1. Oclusal view of the lesion. Extending from the buccal to the palatine side, rough surface, sessile base and normal color.

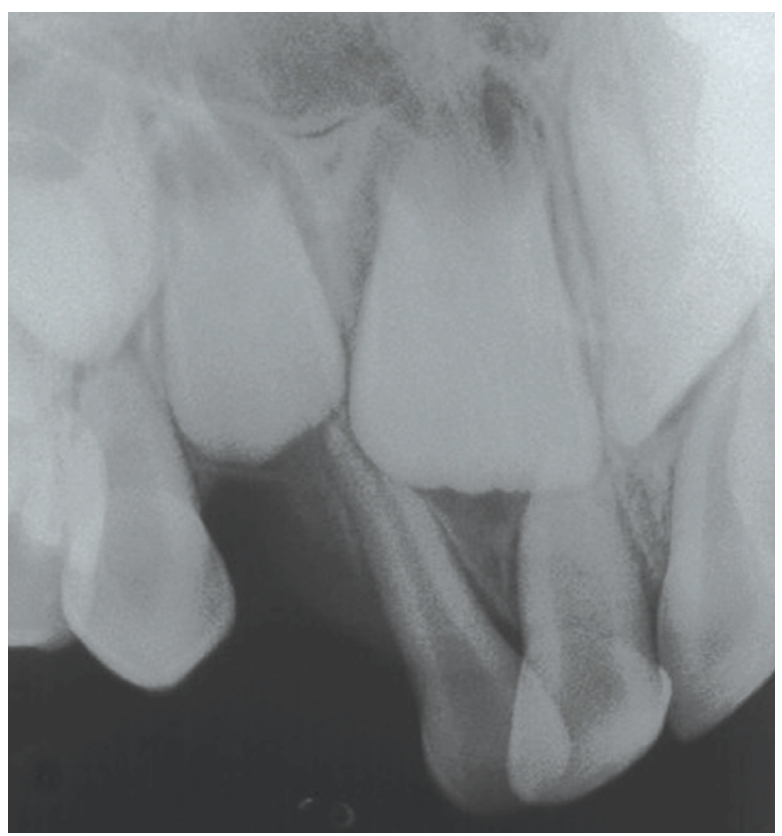

Figure 2. Periapical radiograph showing dental diversion due to the lesion. 


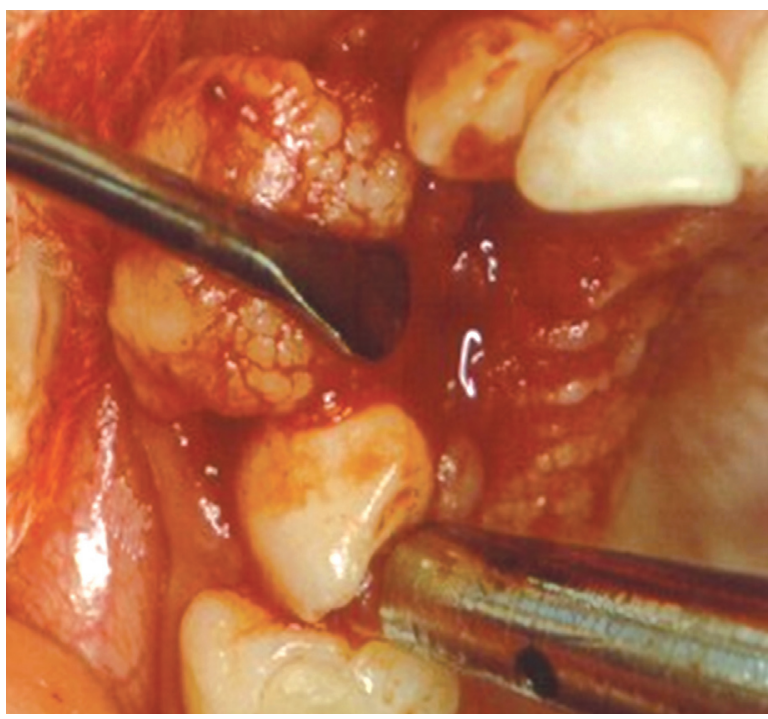

Figure 3. Excisional biopsy, subgingival scaling of the adjacent teeth and coaptation suture.

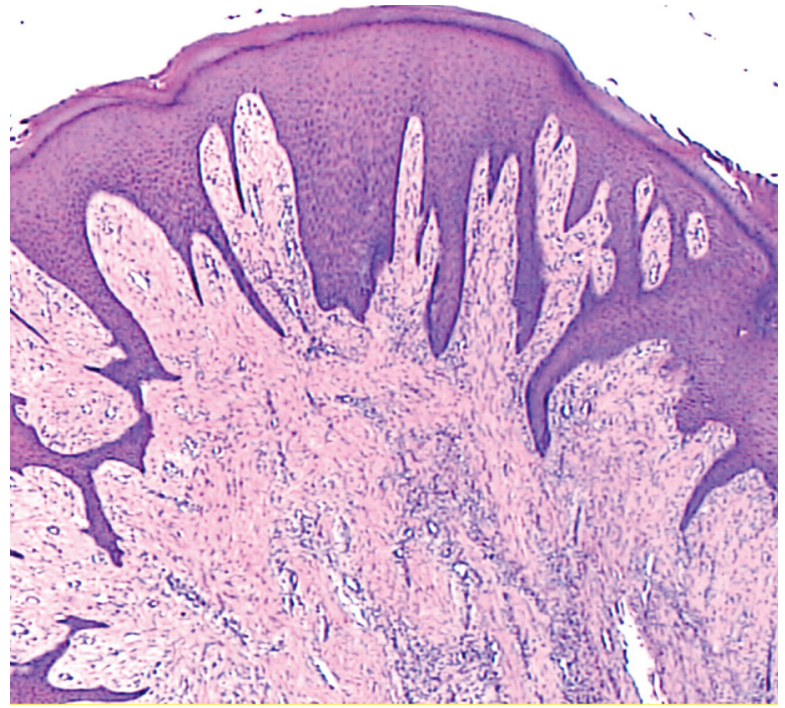

Figure 4. Increase of 50x. Keratinized stratified pavement epithelium with long and thin prolonged, fibrous stroma the cellularized connective tissue.

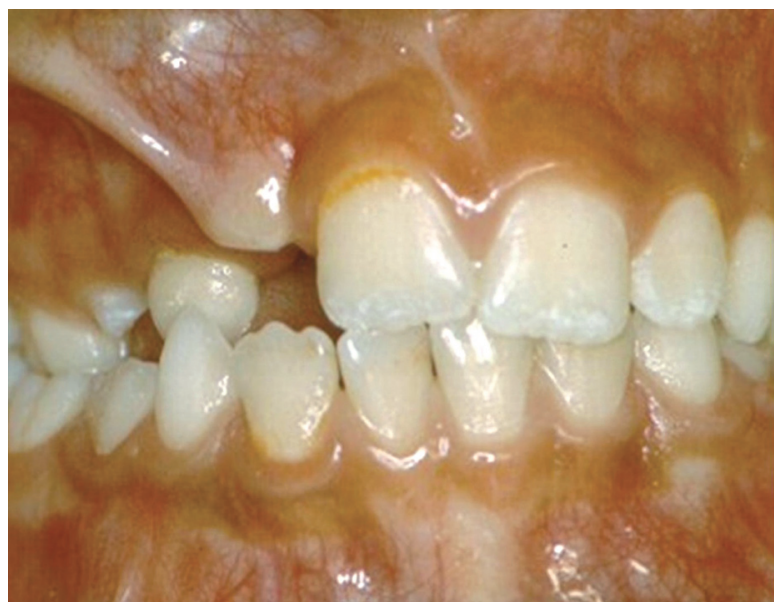

Figure 6. Submucosal inclusion of tooth 12 and normal color of adjacent mucosa.

\section{DISCUSSION}

We presented here a case of PCOF in a 5-yearold child. According to Cuisia and Brannon, ${ }^{4}$ the prevalence of this type of tumor in children aged 5 to 9 years is $10 \%$. In contrast, Kenney et al $^{1}$ reported a $1.9 \%$ prevalence of this lesion in children aged 0 to 9 years.

Eversole and Rovin ${ }^{8}$ stated that the constant irritation present during exfoliation of the deciduous teeth and eruption of the permanent teeth may result in an increased incidence of reactive lesions which originate from the periodontal ligament.

Despite reports of PCOF in children with deciduous or mixed dentition, few data are available regarding the specific occurrence of this lesion involving the deciduous dentition. Hanemann et $\mathrm{al}^{9}$ reported the presence of PCOF in the anterior region of the maxilla of an 11-

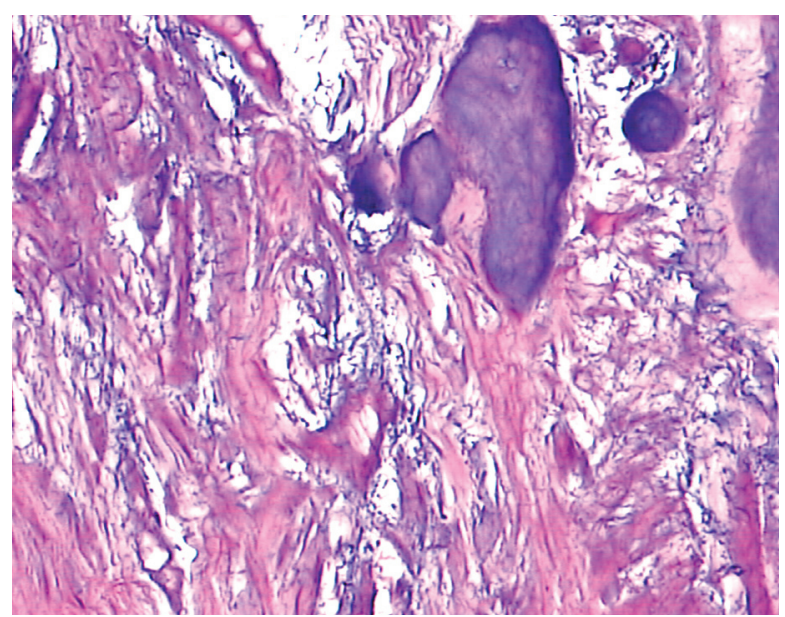

Figure 5. Increase of 400x. Mineralization focuses resembling cementum.

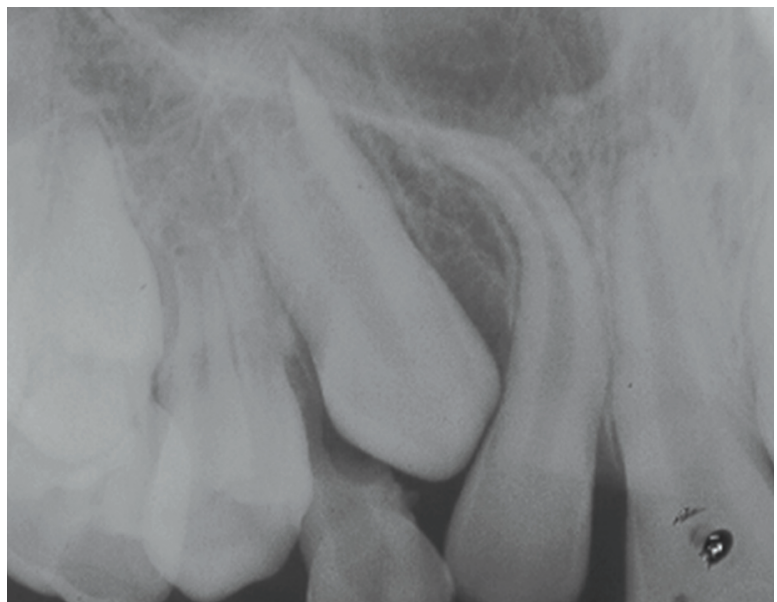

Figure 7. Periapical radiograph shows normal radiopacity of the bone tissue and apical dilacerations of tooth 12 . 
year-old boy with an evolution of 6 months, which appeared after orthodontic treatment. Pérez and Lope $^{10}$ reported the case of a 6 -year-old boy with a 1-month history of this tumor located in the hard palate close to the palatine rugae, which appeared after exfoliation of tooth 61. In contrast, Kohli, Christian and Howell ${ }^{11}$ reported the case of a 7-month-old infant in whom this lesion was observed in the anterior region of the lower alveolar margin associated with a neonatal tooth. In a clinical trial, Cuisia and Brannon ${ }^{4}$ analyzed 134 cases of PCOF in children ranging in age from 1 to 19 years, with a mean age of 14 years.

Gardner ${ }^{12}$ recommended that the term PCOF be used to describe a common, non-neoplastic lesion that shows histopathological characteristics of a fibrous cellularized stroma containing a variety of mineralized material, differentiating it from peripheral odontogenic fibroma which is characterized by odontogenic epithelium and dysplastic dentin. Histologically, PCOF shows a parakeratinized and hyperplastic epithelium and well-cellularized connective tissue containing mineralized components ranging from bone to cementum and, less frequently, dystrophic calcifications. Orkin and Aimadas ${ }^{3}$ emphasized the importance of histopathological examination to confirm the diagnosis of PCOF, which clinically resembles a pregnancy tumor, epulis fibrosa, inflammatory hyperplasia, or peripheral and central giant cell granuloma.

PCOF can show diffuse radiopaque calcification but not all lesions exhibit these radiographic characteristics. Most lesions are not associated with bone destruction. ${ }^{3}$ A case of severe destruction of adjacent bone structures has been reported in the literature, ${ }^{13}$ while discrete bone resorption under the crown of the affected tooth was observed in the present case. PCOF can cause erosion of alveolar bone and tooth separation and interfere with or delay tooth eruption. ${ }^{4}$ In the present case, the lesion caused separation of teeth 52 and 53 . Total excision of the lesion is preferred and should include the periodontal ligament and periosteum, as done in the present case, because recurrence is more common when the basis of the lesion remains. Any irritant etiological factor such as calculus, an ill-adapted orthodontic appliance or rugose restorations should be removed. However, extraction of adjacent teeth is rarely required in the early stages of the tumor. ${ }^{13}$

\section{REFERENCES}

1. Kenney JN, Kaugars GE, Abbey LM. Comparison between the peripheral ossifying fibroma and peripheral odontogenic fibroma. J Oral Maxillofac Surg 1989;47:378-382.

2. Walters JD, Will JK, Hatfield RD, Cacchillo DA, Raabe DA. Excision and repair of the peripheral ossifying fibroma: a report of 3 cases. J Periodontol 2001;72:939-944.

3. Orkin DA, Aimadas VD. Ossifying fibrous epulis. Oral Surg Oral Med Oral Pathol 1984;57:147-148.

4. Cuisia ZES, Brannon RB. Peripheral ossifying fibroma a clinical evaluation of 134 pediatric cases. Pediatr Dent 2001;23:245-248

5. Das S, Das AK. A review of pediatric oral biopsies from a surgical pathology service in a dental school. Pediatr Dent 1993;15:208-211.

6. Bodner L, Dayan D. Growth potential of peripheral ossifying fibroma. J Clin Periodontol 1987; 14:551-554.

7. Neville BW, Damm DD, Allen CM. et al. Oral and Maxillofacial Pathology. Philadelphia: W.B. Saunders; 1995.

8. Eversole LR, Rovin S. Reactive lesions of the gingiva. J Oral Pathol 1972;1:30-38.

9. Hanemann JAC, Pereira AAC, Ribeiro Júnior NV, Oliveira DT. Peripheral ossifying fibroma in a child: report of case. J Clin Pediatr Dent 2003;27:283-285.

10. Pérez CC, López Z. Fibroma osificante periférico. Reporte de un caso y revisión de la literatura. Acta Odontol Venez $1999 ; 37: 45-46$.

11. Kohli K, Christian A, Howell R. Peripheral ossifying fibroma associated with a neonatal tooth: case report. Pediatr Dent 1998;20:428-429.

12. Gardner DG. The peripheral odontogenic fibroma: An attempt to classification. Oral Surg Oral Med Oral Pathol 1982;54:40-48.

13. Poon CK, Kwan PC, Chao SY. Giant peripheral ossifying fibroma of the maxilla: Report of a case. J Oral Maxillofac Surg 1995;53:695-698. 